\title{
Future Outlook of Artificial Cavity Application for Reducing Hydrodynamic Resistance of Containerships
}

\author{
Valery Borusevich ${ }^{1}$, Alexander Poustoshny ${ }^{1}$, Andrey Sverchkov ${ }^{1}$ and Giorgio Trincas ${ }^{2}$ \\ 1. Krylov State Research Centre, St. Petersburg, 196158, Russia \\ 2. Department of Engineering and Naval Architecture, Institute of Naval Architecture, Trieste 34126, Italy
}

Received: November 16, 2016 / Accepted: November 24, 2016 / Published: March 31, 2017.

\begin{abstract}
Absolute commitment to reduce the impact of greenhouse gas emissions while increasing fuel efficiency and power density requires further enhancement of prime mover characteristics and special coatings, but mostly requires compliance with EEDI (energy efficiency design index) measures. For the container shipping industry this represents significant increases in fuel costs that can be mitigated above all by reduction of power demand, that is, of ship frictional resistance. In this respect, this paper discusses advantages attainable by application of the ACS (air cavity system) technology on the basis of recent KSRC (Krylov State Research Centre) studies. Savings in operating costs yielded by the enhanced propulsion performance for ships fitted with this system are illustrated by a case study of a containership.
\end{abstract}

Key words: Air cavity, containership, fuel saving, energy efficiency, green ship.

\section{Introduction}

Year 2025 is drawing near when, according to ambitious standards worked out by the IMO's MEPC (Marine Environment Protection Committee), the EEDI (energy efficiency design index) of the ships built on or after 2015 must be gradually made smaller with the aim to reduce the $\mathrm{CO}_{2}$ emissions of newbuild ships. The EEDI mandatory regime is set out in "Regulations on Energy Efficiency on Ships", Resolution MEPC.203 (62) via an amendment to MARPOL, Annex VI [1]. Even though energy saving was at all times a great concern, for the shipbuilding industry the EEDI coming into force is historically a breakthrough.

There are two ship-specific indexes that indicate whether a ship complies with the EEDI regulations or not. The first is the required EEDI which must be higher than the attained EEDI for any deadweight of a specific ship category.

Corresponding author: Valery Borusevich, Ph.D., research field: propeller cavitation.
At design stage, the required EEDI provides the maximum allowable value in terms of individual ship's emission rate expressed in grams of carbon dioxide $\left(\mathrm{CO}_{2}\right)$ depending solely on the ship type and deadweight of the ship. For each considered ship type the prescribed reference line is the result of a simple formula developed within the IMO from regression over existing database. By this reference line, a ship is seen as environmentally efficient as much as she is slow and large. On the other side, the attained EEDI is the actual calculated value for an individual ship based on fuel type, percentage of deadweight tonnage, percentage of the rated installed shaft power, and reference speed at design load. It indicates the efficiency that is expected for a ship, taking into account the energy required for propulsion, auxiliary systems and hotel services with respect to transport work (deadweight times ship speed). Verification that the attained EEDI-value is lower than the required EEDI-value has to be based on the towing test results (or on sea trials upon agreement of ship owner, ship builder and with approval of the verifier) in order to 
obtain the IEE Certificate (international energy efficiency certificate) before the start of building of the ship.

It is practically the end of the line for lightship weight optimization because consequent reduction of power requirements for slow and large ships is almost irrelevant. So there do remain substantially only two viable ways to reduce hazardous emissions: to enhance performance of the machinery (main engine, auxiliary machinery, waste heat recovery) or to optimize the overall performance of the hull- propeller system. This paper investigates the latter way in hydrodynamic terms.

The progress in calculation methods practically exhausted the potential of hull form improvement and optimization of main dimensions as the path to reduced resistance: today, the maximum reduction these methods can offer is only 3-5\%. Advanced hull coatings for the underwater hull (anti-fouling, anti-friction and self-polishing paints) have been in use for years and, despite their high efficiency, cannot yield any considerable gain either. Special energy saving devices enhancing the efficiency of propulsion system (Mewis duct, rudder bulb, Grim vane wheel, boss cap fins, pre-swirl stator, post-swirl fins, etc.), may reduce fuel consumption by not more than $4 \%$. As it is difficult to gain more than a few percent by these energy saving devices, so far in the container industry the most productive way to reduce emissions has generally been the common use of the slow steaming profile, i.e. operation of ships at lower speeds.

As the frictional resistance is by far the largest resistance component in ocean-going ships, any reduction of this component must be searched for extensively. The Columbus egg is to reduce the wetted surface area by separating the ship bottom from the water. The idea to use an air shield to this purpose, thus reducing frictional resistance, is not new at all. It was first suggested in the middle of the 19th century by Stevens, R. L. \& Stevens, F. B. [2].

There are three main ways to use air for this purpose: air film, air bubbles and air cavities. Bubbles and air films have been tried out on real ships. The bubbling option is quite attractive because of its practicability in ships' retrofit.

However, its effectiveness in terms of resistance reduction is very controversial: from $10 \%$ to zero, according to various publications. The report of the European Union project SMOOTH [3] has stated that air film and micro-bubble technologies are still far from practicable application in shipbuilding. Full-scale measures on "Till Deymann", an inland navigation vessel fitted with a compressor system which used a special device to generate micro-bubbles, had not shown any significant reduction in effective power at full scale, albeit the model tests had shown notable gains. That is probably because physics of friction drag reduction by means of bubbles still remains unclear [4].

On the contrary, the physics of the air cavity technology is simple and does not suffer considerably for scale effects. The unsatisfactory results obtained by several companies do not allow anybody to be skeptical and derive pessimistic conclusions about the contribution such an advanced technology in ship hydrodynamics can give to reduction of EEDI and GHG (greenhouse gas emissions). The pessimistic mood of many shipping circles on this subject is not explicable if one looks at results obtained in Russia on different ship types by installation of the ACS (air cavity system).

This paper provides a brief overview of the results achieved by the KSRC (Krylov State Research Centre) in developing and applying the ACS technology. The challenges that still persist for ocean-going ships are outlined. Simulating a voyage of a large containership in an operating lane from Northern Europe to Far East quantitatively assesses the potential savings in operating expenditure offered by lower fuel demand achievable by means of the ACS technology.

\section{Commitment to Energy Efficiency}

There is a continued pressure on fuel price and 
emissions reduction due to increasingly demanding environmental regulations which compel to innovative solutions. Indeed, the ongoing volatility of fuel prices, the evolving regulatory framework and the projected exponential growth of global ocean-going ship tonnage predicted to double by 2030, are the driving factors that are establishing the future energy requirements for the sea transportation industry. Even though GHG emissions of shipping industry account only $3 \%$ of global emissions, this share is expected to be at least doubled, even tripled, by 2050 due to growth of international trade and the associated transport demand, if no attentive action is taken. EEDI mandatory requirements for specific categories of ships are just a first attempt to prevent harmful and excessive emission of GHG.

Most major container companies are already building and are planning to build larger and more efficient ships that will increase capacity while reducing overall costs. Together with the common use of slow steaming to save money and full utilization of tonnage, this general shift in the container industry could create a container fleet nearly as efficient as an EEDI-compliant fleet, notwithstanding the date of regulations' implementation. Because of the fleet size and the high potential future demand, containerships account for both the majority of projected savings and the most uncertain variable in the growth scenarios.

In the past, fuel price has not been a strong driver in decisions about how to build and outfit new ships. Ship operators face two main annual costs that inform their decisions: ships' capital costs and operating costs, which are ruled by the cost of fuel. Fuel price fluctuates substantially year-to-year and has been, on average, lower than the annual capital cost of the ship itself so that minimizing capital cost has been the primary consideration in designing new ships. The often-cited "split incentive" market failure, deriving from the separation of ship ownership and operation, had emphasized the tendency to minimize the capital costs.

More recently, weighing scale between the annual capital costs associated with new and annual fuel costs has changed significantly such that economic impact of fuel costs is much higher than capital costs [5]. This effectually drives the economics of building fuel efficient ships in the same direction as the EEDI regulation, i.e., diminishing the increased building costs of EEDI compliant ships by stressing the fuel savings also because heavy fuel oil will continue to be the most popular in terms of usage by the shipping industry. Similarly, relatively high fuel prices will support the development of new efficiency technologies, such as ACS, that boost the EEDI rating of ships.

In recent years, annual costs of the container shipping industry have rising significantly because of new sulphur emission regulations that have forced ship owners to use higher cost fuels. These extra costs are further beating an industrial sector already hurt by overcapacity, low demand and falling freight rates. From January 2015 ships entering ECA (emissions control areas) had to switch to fuels with less than $0.1 \%$ sulphur content and an even lower cap of $0.50 \%$ is planned for 2020. According to the Organization for Economic Co-operation and Development [6], implementation of these regulations could lead to increased annual total costs of around USD 5 billion to USD 30 billion for the container shipping industry. Lowering of the EEDI, that is, eco-efficiency improvement, may be obtained nowadays by ships' deadweight increase and/or speed reduction, but most of all by application of innovative technologies such as the ACS.

\section{The ACS Technology}

The air cavity system is not a new technology whatever. KSRC started air-cavity ship development in former Soviet Union back in 1961. Initially, this technology was applied on slow river ships and barges [7, 8]. Since 1965, the air cavity technology was successfully implemented on fast passenger ships and planing craft: fuel consumption was reduced by $20-25 \%$ 
at full speed power; alternatively, the design speed was increased by $10-15 \%$ keeping constant the output of the power plant [9]. In following decades, theoretical developments validated by extensive model tests allowed application of ACS on planing and semi-planing catamarans, fast passenger and passenger/car ferries, fast monohulls with outriggers $[10,11]$. The challenges associated with various types of propulsors, stability-related safety, maneuverability and seakeeping performance have been won. At the same time, problems incurred in fitting various types of propulsion units, e.g., water jets, supercavitating and ventilated propellers, were solved adequately. So far, as regards fast vessels Russian experts have developed eight original designs and shipyards have built over eighty vessels of various purpose fitted with air cavity, their displacement being between 14 and 300 tons.

After many years of studies, a new configuration of the bottom recess was developed, where the longitudinal profile of the air cavities follows the path of the wave profile yielded by the ship herself when running. The main elements of the third-generation ACS are illustrated in Fig. 1. A recess is built in the flat part of the ship bottom where the fore end is delimited by a transverse wedge. The recess sides are restricted by intermediate transverse steps and longitudinal keels which ensure initial stability, prevent air leakage and inhibit air flow from one side to another as the ship rolls. In the aft end, the recess smoothly joins with the bottom by means of a soft slope. A limited amount of air is supplied to the cavities from a blower or a compressor via quite a simple piping bus.

Artificial air cavities reduce the friction and roughness resistance by decoupling a significant portion of the bottom (35-40\% of the total wetted hull surface) from the water. To ensure significant drag reduction, the cavity should have optimal geometry, i.e. large plan area and smooth transition into the bottom. The pressure in the cavity roughly corresponds to the static pressure at the base line level. Stable air cavities are generated by designing special geometry shape of ship bottom in two sequential stages. In the first stage, the geometry of the main elements of the bottom recess (depth, positions of the forward wedge and of the intermediate ones, etc.) is determined. To this end, a 3D linearized theory of cavitation flow is used, which requires ex-ante experimental or theoretical assessment of pressure distribution along the hull without the recess.

Then, the model built with the recess for air cavities is tested in the towing tank. These tests encompass iterative updates of the bottom elements involved in cavity formation, until the best possible result is achieved. Several comparisons between the theoretical
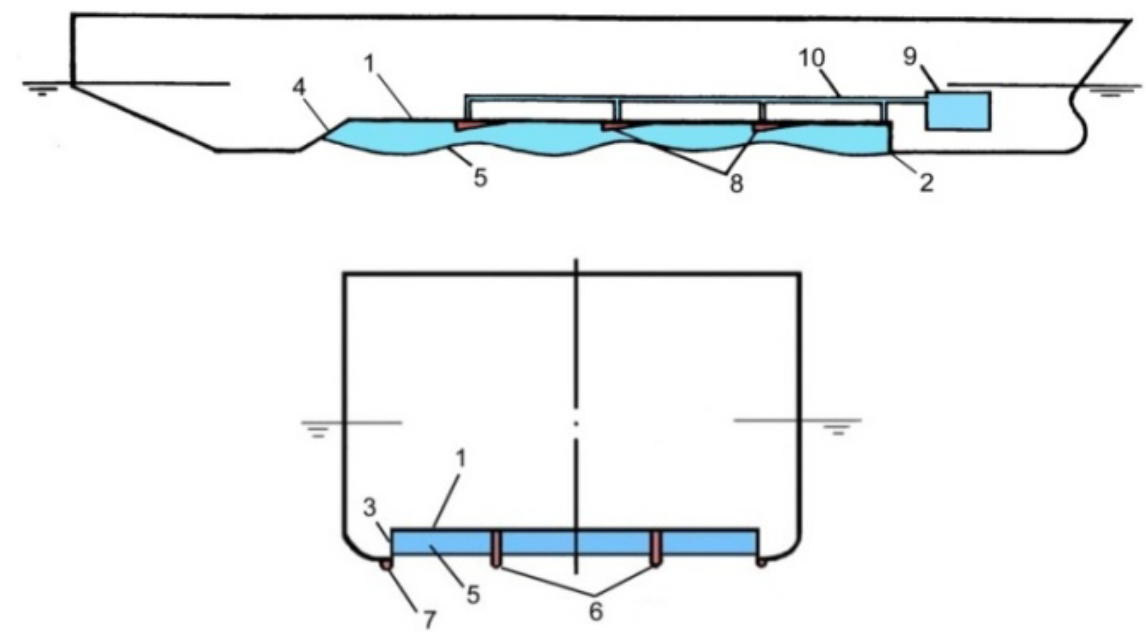

Fig. 1 Sketch of ACS configuration.

1. recess; 2. transverse wedge; 3 . lateral side of recess; 4 . bottom stern slope; 5 . cavity with wave profile; 6 . longitudinal keels; 7 . restrictive side keels; 8 . transverse steps; 9. air blower/compressor; 10. piping bus. 
and experimental cavity profile on a number of ship models have shown good correlation.

So far, as to displacement hull forms KSRC has performed $R \& D$ activities on fourteen original designs of the following carrier ships:

- River-going ships and barges;

- Mixed (river-sea) navigation ships;

- Handymax sea-going bulkers;

- Supertankers;

For all the ships covered by the investigation, at design draught the air cavities yielded $16-25 \%$ resistance reduction within a $0.12-0.21$ Froude number range.

\section{ACS on Ocean-Going Ships}

Based on the analysis of the research results obtained on models of displacement ships as well as according to design studies, the following aspects still require critical examination of the following issues:

(1) Optimal selection of the ship for application of ACS technology depends on two main factors:

(a) The cavity reduces mostly the overall viscous resistance as its effect upon wave resistance is negligible for most of ships. So ACS will perform the best at Froude numbers where resistance is mostly due to friction.

(b) The bottom area covered by the cavity depends on the ship type and hull form. In theory, the area separated from water, i.e. the recess area, should be as large as possible: at least $35-40 \%$ of the entire wetted surface of the ship. The actual value of the recess area depends on ship draught, bottom shape and block coefficient. For fast displacement vessels with low block coefficient, bow and stern will be narrow enough; so the increase of the recess area might require widening the hull, which will certainly increase wave resistance.

Thus, even theoretical studies on the applicability of ACS have shown that this technology will be easier to implement and the most efficient in terms of fuel savings on ships with long parallel midbody, operating at relatively low Froude numbers $F n<0.20$. The ACS may also be applied on ships operating at $F n<0.22$, with about the same effect; in this case, hull lines must be optimized through a tradeoff between identification of a favorable site for the forward boundary of the recess and mitigation of the wave resistance increase.

(2) During tests regarding application of ACS on various types of ships it was found that the cavity is sensitive to trim, which makes it difficult to maintain the cavity stable where trim is relevant as it generally happens during transit of cargo ships at ballast draught. However, a resistance reduction by $12-15 \%$ can be kept by designing a thorough ballast system.

Excessive pitch motion might destroy the cavity. As per model tests in waves, single cavities start splitting into a cluster of cavities as the ship moves in sea states 4-5, depending on the ship size. For a ship with high block coefficient and displacement of $80,000 \mathrm{~m}^{3}$, at model scale it has been shown that instability of the cavity in waves might reduce ACS efficiency by about $20 \%$ at SS5, by $40 \%$ in SS6 and by $90 \%$ in SS7. The larger the ship, the less it is affected by waves and more it is suitable for ACS application.

The restrictions mentioned above might be serious obstacles for ACS application on ocean-going ships. To overcome this challenge, KSRC performed a lot of R\&D activities. In particular, lots of efforts were put into drag reduction of transverse steps when the cavities dissipate because of severe sea state at large trim. As a result, a system of retractable steps was developed, whereas longitudinal keels were kept fixed. Also it can use them as supports when the ship is docking. When steady existence of cavities is impossible, transverse steps can be retracted inside the bottom recess. It was shown that when the steps are retracted, the total resistance of an ACS-fitted ship can be $5-7 \%$ higher than the one with conventional hull. Currently, based on a Russian patent [12], this technical solution is undergoing the procedure of international patenting. 


\section{The ACS Post-Panamax Containership}

The next step of the studies was experimental check and practicability assessment of applying the ACS on a 9500 TEU ISO containership with homogeneous gross weight of 10.5 metric tons per one container. The main goal of this case study was to evaluate the influence on fuel consumption, hence economic and environmental efficiency, when installing the air cavity system on a post-panamax plus class containership. Potential reduction of the operation costs thanks to ACS is assessed through simulation of a typical round trip (Northern Europe-Far East).

\subsection{Development of Alternative Containerships}

A 9500 TEU containership, designated as basis ship, was jointly designed by University of Trieste and Navalprogetti to a level sufficient to check the compliance with intact and damage stability requirements and to perform a preliminary assessment of building and operation costs. The model of this ship was tested in the huge towing tank of $\mathrm{KSRC}$, measuring also the pressure distribution on the hull at design speed. Then the ACS recess was designed and built.

Both variants of the containership have the same geometrical characteristics, see Table 1, and equal deadweight in order to make comparison feasible from both technical and economic viewpoint. It is worth noticing that both ships have a shorter and wider hull with respect to standard container ships of about the same deadweight, so as to obtain a larger flat bottom to facilitate a sufficient recess area.

Service speed of both ships is $19 \mathrm{kn}(F n=0.167)$ at sea state $4-5$ (sea margin 18\%) and power is rated as

Table 1 Maincharacteristics of the container ship.

\begin{tabular}{ll}
\hline Length overall $(\mathrm{m})$ & 338.50 \\
Length water line $(\mathrm{m})$ & 312.00 \\
Beam $(\mathrm{m})$ & 45.60 \\
Draught $(\mathrm{m})$ & 14.75 \\
Block coefficient & 0.664 \\
Design speed $(\mathrm{kn})$ & 19 \\
Deadweight $(\mathrm{t})$ & 104,000 \\
\hline
\end{tabular}

$90 \%$ MCR. Ship endurance is $11,000 \mathrm{~nm}$ with $10 \%$ of fuel remaining. The ship is assumed to perform regular voyages on the operation lane Rotterdam-Hong Kong (19,500 nm round trip).

\subsection{Model Tests of the ACS Containership}

To test the ACS efficiency, KSRC manufactured a model of the containership, scale 1 : 70. Initially, the model of the conventional hull form was built and tested. Then, a recess was designed and built in its bottom (Fig. 2), with the aft slope and two longitudinal keels installed.

The area of the recess made $34.64 \%$ of the wetted surface area; relative volume of the recess being $4.38 \%$ of the ship's displaced volume.

Fig. 3 shows the underwater photo of the bottom of the ACS-fitted ship model with the bow in the foreground, at the full-scale design speed.

Assessment of the towing power $P E$ for the basis hull and the variant with ACS in calm weather condition



Fig. 2 Containership model with the recess.

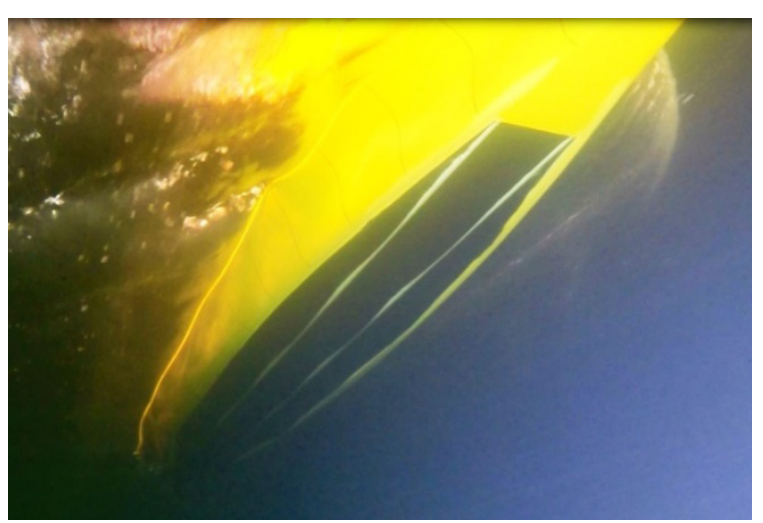

Fig. 3 Underwater hull of the ACS model. 


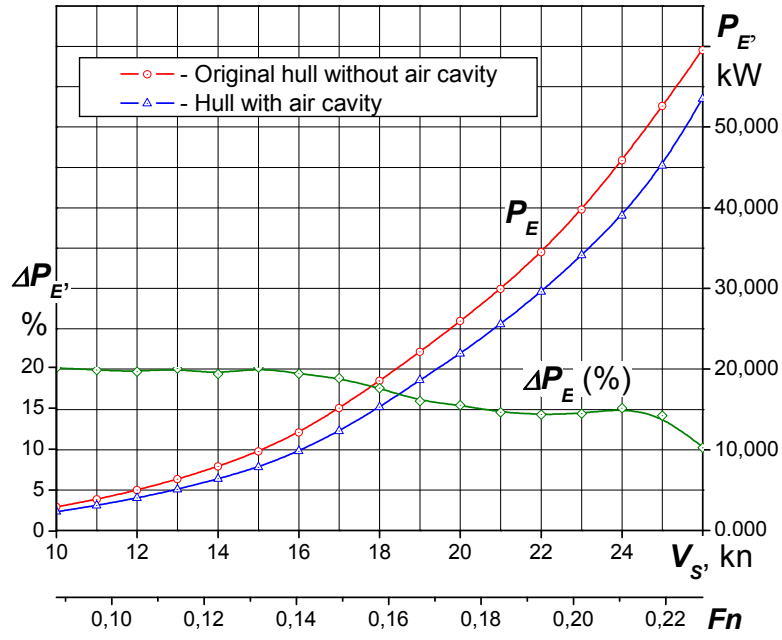

Fig. 4 Towing power reduction yielded by the ACS.

is shown in Fig. 4 together with the obtained reduction in towing power, $\Delta P_{E}$.

Extrapolation of the test results to full scale for both the basis hull and the ACS hull has shown that at full-scale speed of 19 knot the cavity yields about 16\% towing power saving. Based on the resistance of model tests, a power prediction was made by designing two different propellers (see Table 2 where propulsion coefficients are assumed equal). Of course, the quasi-propulsive coefficient of the ACS-fitted ship is higher since the corresponding propeller is less loaded.

It should be noted that the ship speed refers to the design draft and the continuous service rating (CSR $=$ $90 \% \mathrm{MCR}$ ) including $18 \%$ sea margin.

Power demand for air supply will never exceed $2 \%$ of main engine power. The ACS ship shall have two air compressors (main and standby) with power of $600 \mathrm{~kW}$

Table 2 Powering performance prediction.

\begin{tabular}{lll}
\hline Hull configuration & Basis ship & ACS ship \\
\hline Towing power $(\mathrm{kW})$ & 22,130 & 19,060 \\
Type of propeller & FPP & FPP \\
Propeller diameter $(\mathrm{m})$ & 9.050 & 8.760 \\
No. of propeller blades & 6 & 5 \\
Expanded area ratio & 0.740 & 0.689 \\
Pitch-diameter ratio & 0.859 & 0.885 \\
Advance coefficient & 0.496 & 0.501 \\
Quasi-propulsive coefficient & 0.684 & 0.696 \\
Shaft power $(\mathrm{kW})$ & 38,820 & 32,860 \\
Brake power $(\mathrm{kW})$ & 42,910 & 36,780 \\
\hline
\end{tabular}

each, air supply rate around $8,000 \mathrm{~m}^{3} / \mathrm{h}\left(2.2 \mathrm{~m}^{3} / \mathrm{s}\right)$ at pressure of $0.25 \mathrm{MPa}$. All these considered, the competitive ships could be driven by two-stroke engines Wärtsilä X92 with 7 and 6 cylinders for the basis and the ACS containership, respectively.

The lower cost of the diesel engine installed on the ACS-fitted ship would compensate the higher building cost of this ship due to material (hull steel, blower, piping bus) and working hours.

\section{Evaluation of ACS Advantages}

The advantages inherent in the ACS technology could be exploited in different ways:

(a) To keep the service speed constant and the same main engine, so increasing the ship size, hence deadweight;

(b) To keep the cargo capacity constant and the same main engine, and instead increase the ship speed to obtain a higher number of turn-round voyages per year;

(c) To keep the transport capacity constant and the same ship speed while reducing the required engine power output, hence fuel consumption and operating costs.

In this paper the hypothesis (c) has been taken, because it makes irrelevant both imprecision and uncertainty related to acquisition cost estimate of alternative designs. However, the errors and inaccuracies in the cost assessment are of little importance for comparison of the containership alternatives that, as mentioned above, have the same deadweight and service speed. More profound understanding of the operational rules applied by a shipping company together with a probabilistic approach in engineering economics could provide a more accurate structure of the costs.

\subsection{Effect of ACS on EEDI}

EEDI has been created in order to directly reflect the carbon dioxide emissions of a ship under design, even though this index might be more effective if it were more biased towards the need to encourage investment in a technology like ACS and/or if deadweight would 
be replaced by payload.

As stated before, the attained EEDI must be lower than the required EEDI obtained from the reference line valid for the containerships, which will be made tighter over time in three phases (see Fig. 5). For large containerships, with reference to the mentioned line required in phase 0 (contract date after January 2013), new buildings require to be $10 \%$ more efficient after 2015, 20\% more efficient by 2020 and $30 \%$ more efficient by 2025 .

The attained EEDI figures have been calculated for both the conventional and the ACS containership based on $75 \% \mathrm{MCR}$ and $70 \%$ of maximum deadweight [13]. The $\mathrm{CO}_{2}$ emissions from the auxiliary engines have been computed based only on main engine power. Favorable correction factors such as that for installed waste heat recovery system have not been applied.

As can be seen, the attained EEDI figures are lower than the reference figure for both ships. In particular, the ACS-fitted ship has an EEDI-value which will meet the required EEDI up to 2025. This value is around two points lower than the attained EEDI for the basis ship, e.g. 15.0 versus 17.0 . It is evident that standard 8,000-10,000 TEU containerships are placed around the reference line of phase 1 , so requiring that new buildings have to become more efficient since the beginning of the next decade to fulfill future requirements (from phase 1 to phase 3). On the other side, from these results it appears that to obtain $10 \%$ reduction of $\mathrm{CO}_{2}$ requires more than $15 \%$ of power output reduction.

In the magic triangle of interaction components between EEDI and ship design, contribution from hull design and machinery systems is reaching the zenith, while a lot can be done in the energy efficient technology, especially in the field of hydrodynamics. This issue is already considered in the formula for the attained EEDI under the header "Guidance on Calculation and Verification Treatment of Effects of Category (B) Innovative Technologies" (Annex 1 of [14]). But, as stated above, the referred air bubble lubrication system is not a reliable solution to achieve significant propulsion power reduction.

On the contrary, experimental results obtained so far show that the optimization potential of the ACS technology in reducing GHG emissions strongly helps to satisfy the EEDI target. Indeed, according to EEDI regulations if a ship shall operate at a reference speed, only a permissible maximum engine power can be installed into the ship. This results in a permissible resistance of the ship at that speed. Assuming that the transport capacity is fixed and wave resistance is minimized, only the frictional resistance may be attacked. And, in this respect, ACS is the way ahead.

That is why, even though EEDI violates some basic hydrodynamic principles [15], the diffuse criticism which states that many ships would require negative wave resistance to fulfill the EEDI is quite disputable after the dogma of impossibility to reduce frictional resistance is going to be destroyed.

\subsection{Economic Estimates}

Once ACS technology is shown to yield a significant reduction in power demand, the next fundamental consideration is the cost effectiveness of the system.

Table 3 shows annual-based economic estimates at design speed for both the conventional containership and the ACS-fitted ship. Calculations were made for three different prices of IFO 180 as provided by Bunkerworld in Rotterdam on three dates, where the minimum was on 18 January 2016.

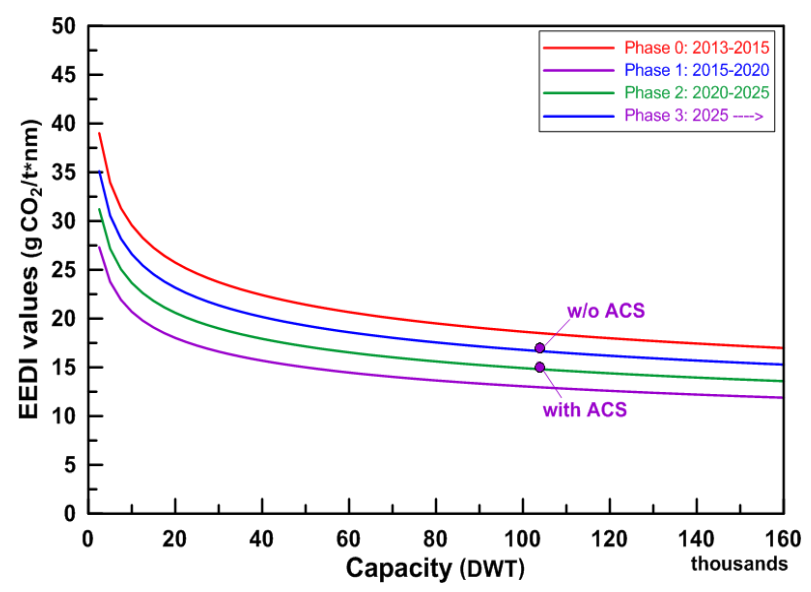

Fig. 5 Attained EEDI versus required EEDI values. 
When multiplying the propulsion power demand with a specific fuel oil consumption of $190 \mathrm{~g} / \mathrm{kWh}$, the daily fuel consumption was found. Compared with the basis ship, the daily reduction of fuel consumption is about $15 \%$.

Any of the economic parameters yields positive result indicating the design with the highest investment potential, where the ACS technology offers reduction in nominal power and lower fuel demand.

The bar diagram in Fig. 6 summarizes savings in annual fuel expenditure by comparing the total main engine operating costs per year, 275 days/year, and distinguishing among fuel prices to take into account their volatility in recent years.

It is assumed that higher costs incurred in hull bottom building together with blowers and piping bus expenditure are compensated by reduction in main engine acquisition cost.

The relative savings in operating costs expressed as NPV (net present value), with the conventional containership used as basis, are given in Fig. 7. The diagram indicates that an NPV saving after 25 years about 38.6, 14.0 and 25.8 million USD for the 375,136 and $251 \mathrm{USD} / \mathrm{t}$ fuel price, respectively, where interest inflation rate correspond to expected values in the European Union.

Table 3 Annual fuel cost savings (million USD).

\begin{tabular}{lcc}
\hline Hull configuration & Basis ship & ACS ship \\
\hline Daily fuel consumption (t/d) & 161.6 & 136.8 \\
\hline Round voyage: Rotterdam-Singapore-Hong-Kong \\
\hline Days at sea per cycle & 44 \\
Cycles per annum & 6.25 & \\
Annual fuel consumption(t/y) & 44,440 & 37,650 \\
\hline IFO180-Bunkerworld on 01/06/2015-375 USD/t \\
\hline Annual fuel expenditure & 16.660 & 14.120 \\
Annual fuel cost saving & 2.540 \\
\hline IFO180-Bunkerworld on18/01/2016-136 USD/t \\
\hline Annual fuel expenditure & 6.040 & 5.120 \\
Annual fuel cost saving & 0.920 \\
\hline IFO180-Bunkerworld on 01/06/2016-251 USD/t \\
\hline Annual fuel expenditure & 11.150 & 9.450 \\
Annual fuel cost saving & 1.700 & \\
\hline
\end{tabular}

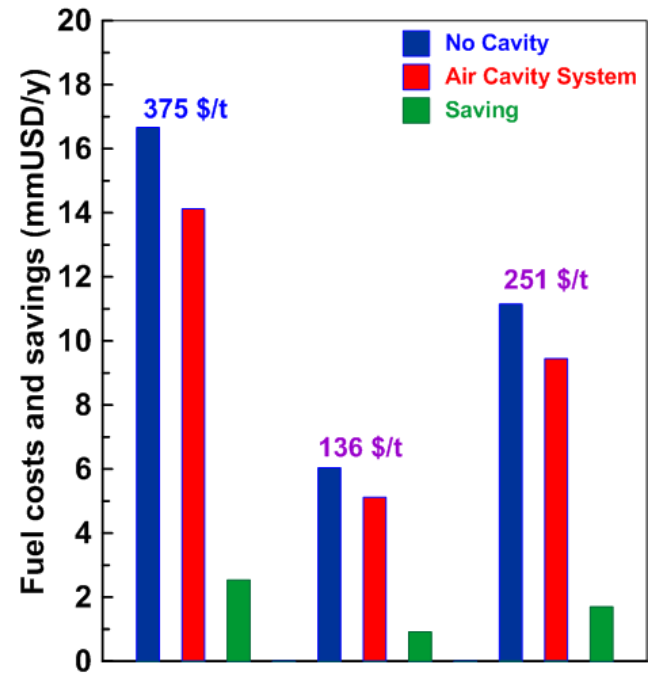

Fig. 6 Comparison between annual fuel costs and savings for different IFO180 Bunker world prices in Rotterdam.



Fig. 7 Savings in operating costs (NPV).

The engineering and economic analysis has shown the following:

- Additional income due to lower fuel demand will be significantly higher than the marginal costs required for ACS installation even for retrofitted container ships.

- Lower fuel expenditure in the range 1.0-2.5 million USD per year, according to fluctuation of fuel price in the last year, for a 9500 TEU ACS containership operating about 275 days a year at slow steaming.

- Lower air pollution at sea, as required by IMO.

- Additional investment in retrofitting a container-ship with ACS will be compensated by an 
average fuel cost payback of 2-3 years, depending on bunker fuel price, dockyard costs, ship size and operational speed.

\section{Conclusions}

In an industry which is very cautious about changes, especially when it involves innovative technologies, IMO measures aimed at improving ships' eco-efficiency through the EEDI regulatory framework instigate innovation in new technologies for reduced fuel consumption. There is a lot of scope for reducing GHG emissions on containerships by reducing ship resistance. To comply with environmental requirement, the ACS energy efficient technology is the most promising and, probably, the only one that can yield $15-20 \%$ reduction in EEDI of ocean-going ships, while offering added value at all levels, both strategic and operational.

The case study has shown that investment in innovating containerships with ACS is technically and financially affordable.

The ACS could be recommended for application on the following types of ships:

- River-going carriers and barges;

- River-sea ships and barge-pusher convoys;

- Ocean-going carriers (supertankers, bulkers, gas carriers, etc.);

- Large containerships;

- High-speed vessels (passenger vessels, patrol vessels, water taxi, service boats, rescue boats, pleasure boats, motor yachts, landing craft, etc.);

- Fast passenger ships.

\section{Acknowledgement}

The authors extend their sincere thanks to the President of Navalprogetti design company L. Cok for his contribution in designing the basis containership.

\section{References}

[1] IMO. 2012. Guidelines on the Method of Calculation of the Attained Energy Efficiency Design Index (EEDI) for New Ships. Resolution MEPC. 212 (63).
[2] Stevens, R. L., and Stevens, F. B. 1848. Improvement in apparatus for the increase of the speed of vessels. US Patent No. 5, 644.

[3] Thill, C. 2010. "A Long Road Mapping Drug Reduction." In Proceedings of the International Conference on Ship Drag Reduction (SMOOTH-Ships), 1-11.

[4] Foeth, E. J., Eggers, R., and Quadvlieg, F. H. H. A. 2010. "The Efficacy of Air-Bubble Lubrication for Decreasing Friction Resistance." In Proceedings of the International Conference on Ship Drag Reduction (SMOOTH-Ships), 115-22.

[5] Stopford, M. 2009. Maritime Economics, 3rd edition, New York: Rootledge, Taylor \& Francis Group.

[6] OECD. 2011. "How Is Industry Responding to Green Growth Imperatives?" Workshop on Green Growth in Shipbuilding, OECD WP6, DG Climate Action, Paris, $1-21$.

[7] Butuzov, A., Sverchkov, A., Poustoshny, A., and Chalov, S. 1999. "State of Art in Investigation and Development for the Ship on the Artificial Cavity." In Proceedings of International Workshop on Ship Hydrodynamics (IWSH'99), China.

[8] Sverchkov, A. 2002. "Perspectives of Artificial Cavity Application Aimed at Resistance Reduction of Ocean/River Ships." In Proceedings of the 3rd International Shipbuilding Conference, 95-100.

[9] Sverchkov, A., and Chalov, S. 1995. "Geometrical Parameters of Artificial Cavities Generated at the Bottom of Semi-planing and Planing Ships." In Proceedings of the International Symposium on Ship Hydrodynamics, 389-93.

[10] Poustoshny, A., Anosov, V., Klichko, V., Lebedev, E., and Sverchkov, A. 2006. "Results of KSRI Last Years Investigations for Fast Ships." In Proceedings of Maritime System and Technology for Defence, Security and Safety (MAST 2006), Nice.

[11] Sverchkov, A. V. 2010. "Application of Air Cavities on High-Speed Ships in Russia." In Proceedings of the International Conference on Ship Drag Reduction (SMOOTH-Ships), 105-11.

[12] KSRC Patent. 2012. Water displacement boat with air cavities on the bottom. WO2012/036595 A1 of 22.03.2012, PCT/RU2011/000708.

[13] IMO. 2009. Interim Guidelines on the Method of the Energy Efficient Design Index for New Ships. Circ.681.

[14] IMO. 2013. Guidance on Treatment of Innovative Energy Efficiency Technologies for Calculation and Verification of the Attained EEDI. Resolution MEPC.1/Circ.815.

[15] Krüger, S. 2011. "Mathematical Evaluation of the Applicability of the EEDI Concept for RoRo Vessel." Harburg Institute of Ship Design and Ship Safety, Hamburg. 